\title{
Employee-Organization Congruence and Job Performance: Development of a Conceptual Model
}

\author{
G.D.N. Perera ${ }^{1}$, A. Khatibi ${ }^{2}$, N.N.J. Navaratna ${ }^{3}$ \\ ${ }^{1} \mathrm{PhD}$ Researcher, Management \& Science University, Malaysia; and Lecturer, Department of Human \\ Resource Management, University of Sri Jayewardenepura, SRI LANKA \\ ${ }^{2}$ Prof and Dean, Faculty of Business Management and Professional Studies, Management \& Science \\ University, MALAYSIA \\ ${ }^{3}$ Senior lecturer, Department of Human Resource Management, Faculty of Management and Finance, \\ University of COLOMBO
}

\begin{abstract}
Research on Employee-Organization Congruence (EOC) has focused on the effect of EOC on individual performances. However EOC and job performance relationship and its contextual validity have not been explored in Sri Lankan apparel sector. This paper has explored the specific factors specially related to the Sri Lankan apparel sector work environment. Among these variables EOC considered as independent variable, job performance as a dependent variable. The conceptual model of this study investigates job related attitudes, namely job satisfaction and organizational commitment as two potential mediating factors for the EOC and job performance relationship. Further organizational climate has been cited as possible moderating factor on EOC and job performance relationship. This paper makes a significant contribution to the body of knowledge with the proposed conceptual framework so that it can be used as a basis for the future research in this context.
\end{abstract}

Key words: Employee-organization congruence, Job performance, Job satisfaction, Organizational commitment, Organizational climate

\section{JEL Classification Code: J53; J58}

\section{INTRODUCTION}

With hot winds of competition blowing across the apparel industry, developing a close symbiotic relationship with employees has become highly important than ever before. When, achieving organizational ultimate objectives, organizations need to understand how people interact with organizational settings and how organizational and individual performance can be improved. Therefore, Person-Environment (P-E) congruence is a general framework that was developed to promote an understanding of how people's characteristics and psychological characteristics interact with the organizational contexts. EOC is one of the major concepts in P-E congruence area (Edwards and Cable, 2009).

EOC is the compatibility of employees skills, attitudes and work values with an organizational entity (Edwards and Cable, 2009; Kristof-Brown et al. 2005). Muchinsky 
(2003) explained job performance is the set of worker's behaviors that can be monitored, measured, and assessed achievement in individual level.

Few researchers (Mackinnon et al.2007; Meglino and Ravlin, 1998 and Meglino et al.1989) revealed the relationship between EOC and job performance, which include the potential mediators and moderators. As a result this study mediates the relationship between EOC and job performance through job related attitudes, namely job satisfaction and organizational commitment. Organizational climate act as a moderator role between EOC and job performance relationship as well as attitudes.

Therefore the purpose of this paper is to propose a theoretical framework so that a future study can explore how job satisfaction, organizational commitment and organizational climate affect to the relationship between EOC and job performance.

\section{SUMMARY OF THE LITERATURE REVIEW}

Person - environment congruence

The concept Person-Environment (P-E) congruence is grounded in the interactions' theory of behavior (Ambrose et al.2008; Edward and Cable, 2009), beginning with Lewin's (1951) propositions that the human behavior is a function of the person and environment. Chatman, (1989) and Kristoff (1996) have shown that the P-E congruence will have a greater interaction with the individual characteristics (psychological needs, personality traits, person factors) and the organizational or situational characteristics (nature of rewards, cultural value and environmental condition).

P-E congruence can be conceptualized with various congruence dimensions including an individual's congruence with a job (person-job), congruence with a group (person-group), congruence with a vocation (person-vocation) and congruence with an organization (person-organization)(Caldwell et al. 2004; Cooper et al. 2004; Jansen and Kristof,2006).

Employee-organization congruence

Employee-organization congruence is embedded in the broader concept of personenvironment congruence. Therefore, the present study provides more attention to the employee -organization congruence.EOC is the compatibility of employees skills, attitudes and work values with an organizational entity (Edwards and Cable, 2009; Kristof-Brown et al. 2005). EOC is generally defined as the "compatibility between individuals and the organizations where they work" (Sekiguchi,2003).

There are three approaches to measuring of the EOC; subjective congruence, perceived congruence and objective congruence (Cable and Judge, 1996; O'Reilly et al.1991). This paper mainly focuses on perceived congruence. Reason is many researchers (Bowen et al.1991; Chatman, 1989; Edward et al.2008; Hamdan, 2011) pay more attention on values between organization and individual. Perceived congruence is an indirect measure where employees are asked to describe both their own personal values and their organizational values (Hamdan, 2011; Meyer et al.2010; O’ Reilly et al.1991; Shar et al.2009).

\section{Job Performance}

Muchinsky (2003) explained job performance (JP) is the set of worker's behaviors that can be monitored, measured, and assessed achievement in individual level. Employee's job performance is important factor to push forward to be excellent organization. Job performance refers to the effectiveness of individual behaviors that contribute to organizational objectives (McCloy et al.1994; Motowidlo,2003). 


\section{Employee-organization congruence and job performance}

Few studies have examined the relationship between the EOC and job performance (Becker et al.1996; Meglino et al.1989; Poon, 2004; Rod, 2008).All these studies conclude negative relationships between EOC and job performance. However, one researcher identified the positive relationship between EOC and JP (Shin and Holland, 2004).According to Kristof's (1996) summary of empirical results, support the positive effects of EOC on employee extra-role behaviors (citizenship performance) and work performance (task performance) (Ambrose et al.2008; Liu et al.2010).In addition, EOC confirms that culture and ideological congruence can affect performance of the organization (Tridball,1988).

EOC has an important implication not only for the employee's affective reactions to organizational life, but also their performance (Kotter and Haskett, 1992).According to Kristof-Brown (2002), perceived EOC is a better predictor of job performance and investigated how employee integrates their perceptions of EOC when forming work attitudes. Further he explained EOC has a unique impact on job performance.EOC related research emphasizes the antecedents and consequences of congruence between employee and entire organization. This congruence is vital in maintaining a flexible and committed workforce that is necessary in today's competitive business environment to achieve goals (Westerman and Cyr, 2004).

Arthur, et al. (2006) have used meta-analysis procedure to estimate the criterion related validity of EOC as a predictor of job performance and turnover. Also compared the relationship with EOC and work attitudes. Analysis data explained the relations of EOC with job performance and turnover were partially mediated by work attitudes including job satisfaction, organizational commitment, and turnover intentions.

Nevertheless, Meta-analyses resulted in estimated true criterion related for EOC as a predictor of job performance. Hoffman and Woehr (2006) extend the meta-analyses of Verquer,et al. (2003) providing a meta-analyses review of the relationship between EOC and behavioral criteria of job performance. They identified 24 studies (conducted between 19672003) between EOC and JP.The results indicated that EOC is weakly related to JP. However, better EOC will result in higher JP in Taiwanese organizations (Silverthorne, 2004).Some empirical studies explained, EOC have a stronger relationship with behavioral outcome of job performance (Ambrose et al. 2008;Cooper et al.2004;Greguras and Diefendorff,2009; Liu et al.2010; Van et al.2007). EOC affects employee performance (Li, 2006).

This study concerned job satisfaction and organizational commitment as mediator variables and organizational climate as a moderator variable. According to Sekaran and Bougie, (2010,p77) a mediator "is one that surfaces between the time, the independent variables start operating to influence the dependent variable and the time their impact is felt on it" Moderating variable is a"presence of third variable modifies the original relationship between the independent and dependent variable" (Sekaran and Bougie, 2010, p73).

\section{Job SATISFAction}

Job satisfaction refers to "an evaluative judgment about the degree of pleasure an employee derives from his or her job that consists of both the affective and cognitive components" (Edwards et al.2008.p442). Aamodt, (2009) defines job satisfaction as "the attitude an employee has toward his job." Most studies focus on the direct relationship between EOC and JP (Chatman, 1989; Lauver et al. 2001; O'Reilly et al, 1991), 


\section{Organizational commitment}

Organizational commitment is the employee's willingness to extend effort in order to achieve the organizational goals and the degree of alignment between the organization goals and values of the employee (Mowday et al.1982). Organizational commitment consists of different types and each type influences on the job behavior differently (Meyer and Allen, 1991).They identified 3 types of commitment, namely affective, normative and continuous commitment. But this study mainly focused on affective and continuous commitment.

\section{Organizational climate}

Organizational climate refers to how the organization's culture - its values, beliefs, and assumptions-are translated into organizational practices, policies, and procedures (Ostroff et al., 2003; Schneider et al., 2000). Bowen and Ostroff (2004) stated that an organization's climate "can act as a strong situation when employees develop a shared interpretation of the organization's policies, practices, procedures, and goals and develop shared perceptions about what behaviors are expected and rewarded in the organization" (p. 207). Litwin and Stringer (1968), who conceptualized the organizational climate in relation to its influence on motivation and behavior. They stated that organizational climate is: "a set of measurable properties of the work environment, perceived directly or indirectly by people who live and work in this environment and assumed to influence their motivation and behavior" (Litwin and Stringer, 1968: p 81).

Mediator and moderator effects on employee-organization congruence and job performance

Few researchers (Mackinnon et al.2007; Meglino et al.1989) revealed the relationship between EOC and job performance, which include the role conflict and the cognitive style as the potential mediators. They described the several theoretical explanations how or why EOC affect for JP and mediators role.In literature, psychological need fulfillment variable has been used as a mediator of EOC (Edwards and Cable, 2009).According to their view, effect of congruence is indirect, and organizational values affect the supplies. As a result, employees were to accept and retain their jobs. Results of the study explained that the indirect effects of value congruence on the outcome were less and further emphasized, the future research will investigate the value congruence effects.

Edwards and Cable (2009) explained the effects of EOC on job satisfaction with mediating variables He founded the relationship with four mediators (communication, predictability, attraction, and trust) and job satisfaction. Further he shown there is no any importance of mediators except of predictability.

Hamdan (2011) investigates role conflict, cognitive style, and industrial justice as three potential mediating mechanisms in the relationship between EOC and individual outcomes. A survey of 558 mid level managers from seven Brunei public sector organizations provided the data. Based on his result, P-O fit and outcome was partially mediated by organizational justice and cognitive style and role conflict has not any mediating effect. According to Morewitz (2009), job satisfaction did not mediate the relationships with EOC and JP. Further he explained, organizational commitment was significantly mediate and organizational climate is not moderate the EOC and JP relationship. 


\section{MetHodology}

This study involves a development of conceptual model for empirical exploration of a phenomenon. Therefore it reviews the existing literature for identifying concepts and relationships relating to the phenomenon. Basically 300 abstracts of articles were scrutinized to check their relevance to the phenomena under consideration. Finally, 200 articles were selected and reviewed for identifying the concepts and relationships involved.

\section{GAPS IN EMPLOYEE-ORGANIZATION CONGRUENCE AND JOB PERFORMANCE}

After reviewing the existing literature, there are three gaps in employee-organization congruence and job performance research as follows.

\section{Gap one}

EOC related researches are very significant and diverse in organizational context. Different studies have been carried out in different organizational setting, different methodology and with different cultural settings. According to the literature review, EOC and JP relationship is not generalized (see relationship of EOC and JP section).Many researchers have found, that there is a relationship between EOC and job performance (Ambrose et al. 2008; Liu et al. 2010; Hamdan, 2011; Rod, 2008), but have not identified as to why better EOC results in better JP, or why better EOC results in lower JP and how low EOC results in lower JP(see figure 1).

\section{Gap two}

As earlier mentioned few studies investigated the mediating effect of EOC and JP. The research question of job related attitudes mediate the relationship between EOC and JP is very vital, because it opens new insight in to the understand of the mediating affect of EOC to the JP in Sri Lankan Apparel Industry. According to the previous sections seems that there is a gap in the empirical knowledge available about the mediating variables role of job satisfaction and organizational commitment to the EOC and JP from the perspective of factory workers in the Sri Lankan apparel sector. The purpose of this study is to find how mediating variables affect to the perceived EOC and JP relationship in the Sri Lankan context (refer figure 3).

\section{Gap three}

As above explained, few studies investigate the moderating effect of EOC and JP. But not finalized how organizational climate moderates the relationship between EOC and JP. Moreover, as there are no previous studies carried out in this area in apparel sector, there is a knowledge gap that could be attempted to address. The literature available to the researcher reveals that there is a wide gap between theoretical as well as empirical explanations of the previous studies. The findings of this study may help to fill this gap to a considerable extent.

\section{Development of the Conceptual Framework}

The proposed conceptual framework was developed based on the identified variables and relations through the literature review pertaining to the research problem of the study. The following contains a brief description of reviewed literature so that it may provide a threshold for the theoretical framework.

Central focuses of the EOC studies are examine the individual outcome, especially job performance (Ambrose et al.2008; Liu et al.2010). Among the EOC studies perceived congruence is the mostly used researched areas (Bowen et al.1991; Edward et al.2008; Hamdan,2011;Meyer et al.2010;O'Reilly et al.1991;Shar et al.2009; Van et al.2007, p.1737).Therefore, relationship between EOC and job performance explained in figure 1. 
Figure 1

Relationship between EOC and job performance

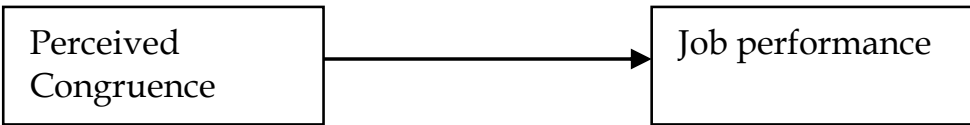

(Source: Adapted by researchers)

Some specific EOC and job performance relationships provide factors which may operate as mediators. This study considers job related attitudes, such as job satisfaction (JS), and organizational commitment (OC) as mediators (refer figure 2).

Figure 2

Relationship between EOC and job performance mediated by attitudes

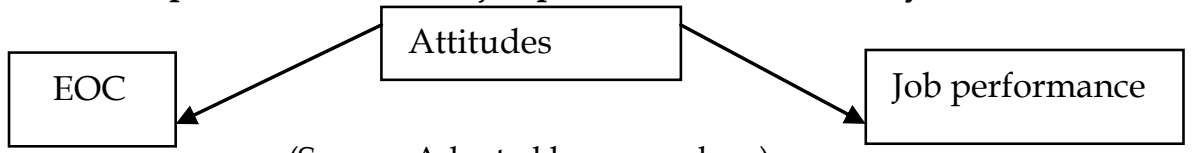

(Source: Adapted by researchers)

Job satisfaction acts as a significant mediator between EOC and JP, because values fit create the strongest situation for the people to satisfy their personal and organizational values. This leads to higher level of satisfaction of the worker to enhance JP.EO incongruence leads to development of the lower satisfaction of a worker that represents the tradeoff between the individual and the organization (Ambrose et al. 2008; Cools et al. 2009; Erdogan and Bauer, 2005). According to the Morewitz (2009) organizational commitment acts as a mediator between the EOC and job performance. EOC meets employees' personal and organizational values to achieve the organizational commitment. This leads to higher level of organizational commitment to the worker with more positive values (individual and organizational) to enhance JP. Figure 3 described job satisfaction and organizational commitment mediate the EOC and job performance relationship.

Figure 3

JS and OC mediate the EOC and job performance relationship

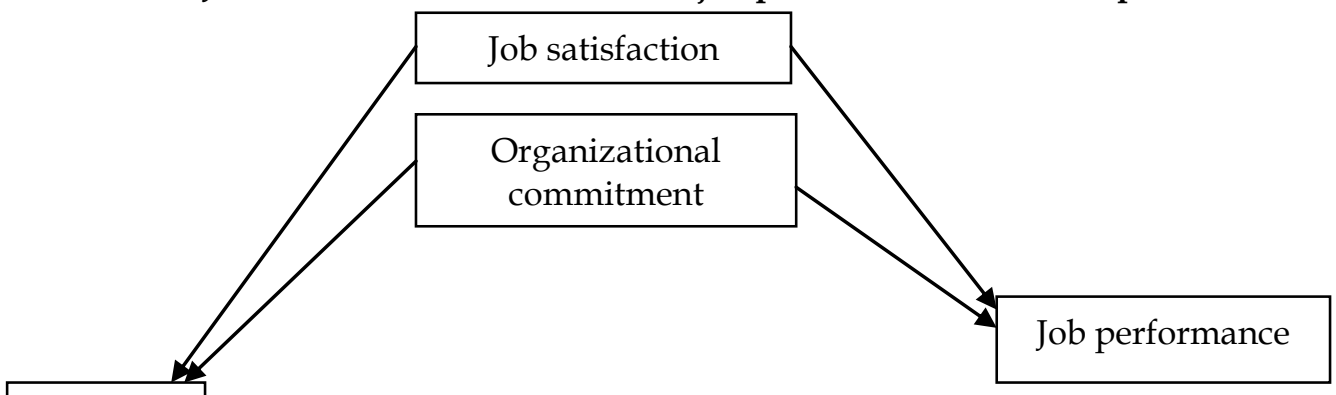

EOC

(Source: Adapted by researchers)

One study (Morewitz, 2009) has been conducted to test the moderating effect between the EOC and job performance by organizational climate. The results indicate that EOC and job performance relationship did not have any significant relationships with the study 
variables (Morewitz, 2009).However, this study wants to identify results are similar or not in Sri Lankan apparel sector.

Figure 4 explained the conceptual framework of this study

Figure 4

Conceptual framework

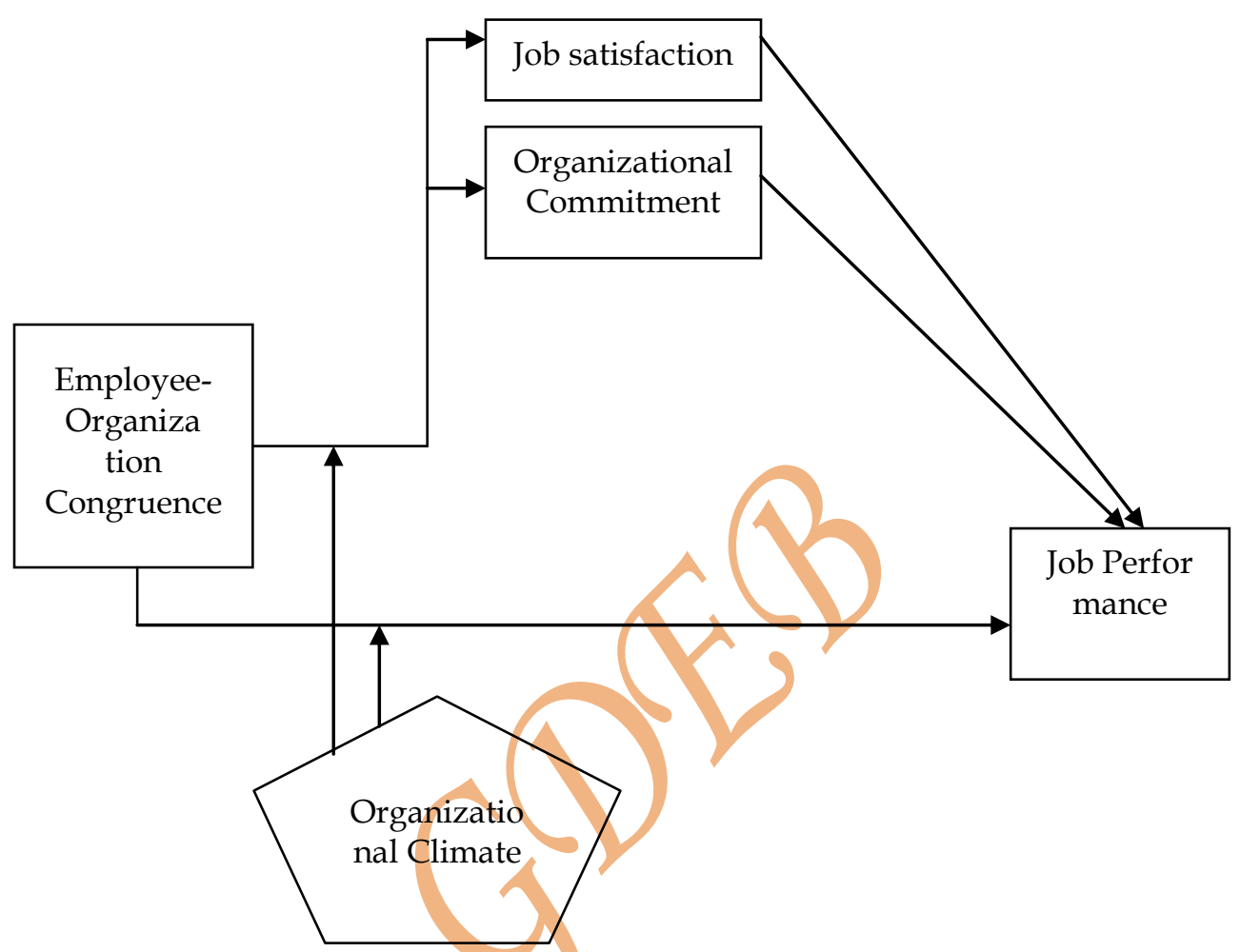

(Source: Developed by researchers)

\section{CONCLUSION AND IMPLICATIONS}

This paper proposes a conceptual framework for exploring the effect of job satisfaction, organizational commitment and organizational climate in the EOC and job performance relationship of the factory workers in large apparel sector. Even though the proposed framework is yet to be tested empirically, the description of the interactions between variables will add significant value to the body of knowledge on both human resource management and organizational behavior literature. First, this paper has offered an extension of the body of knowledge on attitudes by identification of the mediating effect of the job satisfaction and organizational commitment. This paper addresses the knowledge gap of mediating variable effect with EOC and job performance relationship. Next identify how moderator variable effect for the EOC, job related attitudes and job performance relationship. This has not been explored previously. This paper points out this knowledge gap and stress the importance of addressing it empirically. Also identify moderator variable effect for the EOC and job performance relationship. Therefore, proposed conceptual framework of this paper will set a new direction for future research to understand the mediator and moderator effects on EOC and job performance relationship. 


\section{REFERENCES}

[1] Arthur, B., Bell, S T., Villado, A. J. \& Doverspike, D.(2006). The Use of PersonOrganization Fit in Employment Decision Making: An Assessment of Its CriterionRelated Validity. Journal of Applied Psychology. 91 (4). p.786.

[2] Ambrose, M. L., Arnaud, A. \& Schminke, M.(2008). Moral Development and Ethical Climate: The influence of Person-Organization Fit on Job Attitudes. Journal of Business Ethics, 77, 323-333.

[3] Becker, T. E., Billings, R. S., Eveleth, D. M. \& Gilbert N. L. (1996). Foci and bases of employee commitment: Implications of job performance. Academy of Management Journal, 39, 464-482.

[4] Bowen, D. E., Ledford, G. E. \& Nathan, B. R. (1991).Hiring for the organization, not the job. Academy of Management Executive, 5(4), 35-51.

[5] Cable, D.M. \& Judge, T.A. (1996). Person-Organization Fit, Job Choice Decisions, and Organizational Entry. Organizational Behavior and Human Decision Processes,67, pp294-311.

[6] Caldwell, D.F. O'Reilly, C.A. \& Chatman, J. (2004). People and organizational culture: A profile comparison approach to assessing person-organization fit. Academy of Management Journal, 34, 487-516.

[7] Chatman,J.(1989).Improving interactional organizational research: A model of personorganization fit .Academy of Management Review,14:333-349.

[8] Cools,E.,Broeck,H.V. \& Bouckenooghe, D.(2009).Cognitive styles and personenvironment fit: investigating the consequences of cognitive (mis) fit. European Journal Of Work and Organizational Psychology,18(2),167-198.

[9] Cooper,T.H.D,Van,V.A \&Anderson,N.(2004).Changes in Person-Environment fit:The impact of socialization tactics on perceived and actual P-O fit. European journal of Work and Psychology,13.52-78.

[10] Edwards, B.D., Bell.S.T.,Arthur. W. \& Decuir.A.D.(2008).Relationships between facets job satisfaction, task, and contextual performance. Applied Psychology. An International Review, 57, 3, 441-465.

[11] Edwards, J.R. \& Cable, D.M.(2009).The value of value congruence. Journal of Applied Psychology.94 (3).654-677.

[12] Greguras, G.J. Diefendorff, J.M. \& James. M.(2009).Different fits satisfy different needs: Linking person-environment fit to employee commitment and performance using self determination theory.Journal of Applied Psychology,94(2),465-477.

[13] Hackett, R. D., Lapierre, L. M. \& Hausdorf, P. A. (2001). Understanding the links between work commitment constructs. Journal of Vocational Behavior, 58: 392-413.

[14] Hamdan,M.H.,2011.Mediators of the relationship between person-organization fit and outcome. School of Mgt, Faculty of Business, Queensland University of Technology, Australia.

[15] Hoffman, B. J. \& Woehr, D. J. (2006). A quantitative review of the relationship between person-organization fit and behavioral outcomes. Journal of Vocational Behavior, 68, 389-399.

[16] Jansen,K. \& Kristof-Brown.A.(2006).Toward a multi dimensional theory of personenvironment fit. Journal of Managerial Issues.28.193-212.

[17] Kanungo, R.N. (1982). Work alienation: An integrative approach. New York: Praeger Publishers.

[18] Kristof,A.L.(1996), Person-organization fit: an integrative review of its conceptualizations, measurement, and implications. Personnel Psychology, 39, pp1-49.

[19] Kristof-Brown. A.L,Zimmerman. R.D. \& Johnson, E.C. (2005).Consequences of individuals fit at work: A meta analysis of person-job, person-organization, persongroup-person supervisor fit: Personnel psychology 58, 281-342.

[20] Lawler, E.E. (1986). High-Involvement Management, Jossey Bass, SanFrancisco, CA. Management Journal,Vol.33, Pp.692-724.

[21] Lewin.K.(1951).Dynamic theory of personality, New York: McGraw -Hill.

[22] LI, J. (2006). The interactions between person-organization fit and leadership styles in Asian firms, an empirical testing. International journal of HRM. , vol. 17, no. 10, p. 1689-1706. 
[23] Litwin, G. H., \& Stringer, R. A. (1968). Motivation and organizational climate. Boston: Division of Research, Graduate School of Business Administration, Harvard University.

[24] Lodahl, M. K.(1965) The definition and measurement of job involvement Journal of Applied Psychology, 49 . pp. 24-33.

[25] Mackinnon,D.P.,Fairchild.A.J. \& Fritz, M.Z.(2007).Mediation analysis. Annual review of Psychology, 58.593-614.

[26] McCloy, R. A., Campbell, J. P. \& Cudeck, R. (1994). A confirmatory test of a model of performance determinants. Journal of Applied Psychology, 79, 493-505.

[27] Meglino, B.M. \& Ravlin,E.C.,(1998).Individual values in organizations. Concepts. Controversies and research. Journal of Management,24. 351-359.

[28] Meglino, B.M., Ravlin, E.C. \& Adkins, C.L. (1989).A Work Values Approach To Corporate Culture: ATest of The Values Congruence Process and Its Relationship To Individual Outcomes. Journal of Applied Psychology, 74 (3), pp.424-432.

[29] Meyer, J. P. \& Allen, N. J. (1991). A three component conceptualization of organizational commitment. Human Resource Management Review, 1, 61-89.

[30] Morewitz,C.L.(2009). Climate strength as a moderator of the relationship between person-organization fit and job performance.

[31] Motowidlo, S. (2003). Comprehensive Handbook of Psychology, Vol. 12 (pp.39-53). NewYork, NY:Wiley.

[32] Mowday; R. T. Steers, R. M. \& Porter, L. W.(1982) "The Measurement of Organizational Commitment", Journal of Vocational Behavior, Vol.14, pp.224-227.

[33] Muchinsky, P. M. (2003). Psychology Applied to Work (7th ed.). Belmont, CA:Wadsworth.

[34] O'Reilly III, C.A, Chatman, J. \& Caldwell, D.F. (1991). People and organizational culture: A profile comparison approach to assessing person-organization fit. Academy of Management Journal, 34, 487-516.

[35] Ostroff, C., Kinicki, A.J. \& Tamkins, M.M., 2003. Organizational culture and climate. Handbook of Psychology: Industrial and Organizational Psychology, 12. John Wiley, New York, NY, pp. 565-593.

[36] Poon,J.M.L.(2004).Effects of performance appraisal politics on job satisfaction and turnover intention. Personnel review 33(3).322-334.

[37] Rod,M., Ashill, N.J. \& Carruthers,J.(2008).The relationship between job demand stressors,service recovery performance and job outcome in a state-owned enterprise. Journal of Retailing and Consumer Services.15(1),22-31.

[38] Schneider, B.(2001).Fits about fit .Applied Psychology: An International Review,50,141-152.

[39] Schneider,B.,Goldstein,H.W. \& Smith.D. B.(2000).Attraction-selection attrition. Toward a person-environment psychology of organizations, Person Environment Psychology: New directions and perspectives (pp 61-82)

[40] Sekaran,U. \& Bougie,R.,2011.Research methods for business: A skill building approach, $5^{\text {th }}$ edition, Printed in Great Britain by TJ International Ltd,Padstow,Cornwall.

[41] Sekiguchi, T.(2003). A contingency perspective on the importance of P-J fit and P-O fit in employee selection. Paper presented at the Annual Conference of Academy of Management, Seattle, WA.

[42] Tidball, K. H. (1988). Creating a culture that builds your bottom line. Cornell Hotel and Restaurant Administration Quarterly, 29 (1), 63-69.

[43] Van,V.A.E.M, De Pater,I.E. \& Van,D.F.(2007).Work value fit and turnover intention: Same source or different source fit. Journal of managerial psychology,22(2),188-202.

[44] Westerman, J.W. \& Cyr, L. A. (2004). An integrative analysis of person-organization fit theories. International Journal of Selection and Assessment, 12 (3), 252-261. 